\title{
Wide Flange Beams: Trends Towards Higher Steel Performance
}

\author{
Riccardo Zanon*1 and Dario Zaganelli ${ }^{2}$ \\ ${ }^{1}$ Structural R\&D Engineer, Luxembourg \\ ${ }^{2}$ Technical Sales Engineer, Luxembourg
}

*Corresponding author: Riccardo Zanon, Structural R\&D Engineer, Global R\&D, 66 rue Luxembourg, L-4009, Esch-sur-Alzette, Luxembourg.

Received Date: February 01, 2019

Published Date: February 06, 2019

\section{Foreword}

Rolled structural shapes (L, I, H, U) were developed already in the 19th century, answering the need to simplify shapes built up from plates assembled together by rivets. The advantages in terms of weight savings, fabrication simplification, manpower time and cost reduction were integral to the acceptance of rolled shapes in every field of structural steelwork. When it comes to H-structural shape, the flagship plant of Differdange, Luxembourg (Europe) developed the parallel wide-flange beams based on the patent by Engineer Henry Grey (1898). With the first beam rolled out in 1901 and achieving the iconic step of $1 \mathrm{~m}$ tall beam in 1911, the widespread of parallel flange beam was rapid and nowadays has become the standard product of steelwork. Today, the geometric range of available $\mathrm{H}$ structural shapes is extensive (beam height from $80 \mathrm{~mm}$ up to $1150 \mathrm{~mm}$, flange width from $50 \mathrm{~mm}$ up to $476 \mathrm{~mm}$, flange thickness from $4 \mathrm{~mm}$ up to $140 \mathrm{~mm}$ ) with a well-established presence of producers around the world allowing for market competition, product availability and reliable supply chain.

\section{Towards Higher Strengths}
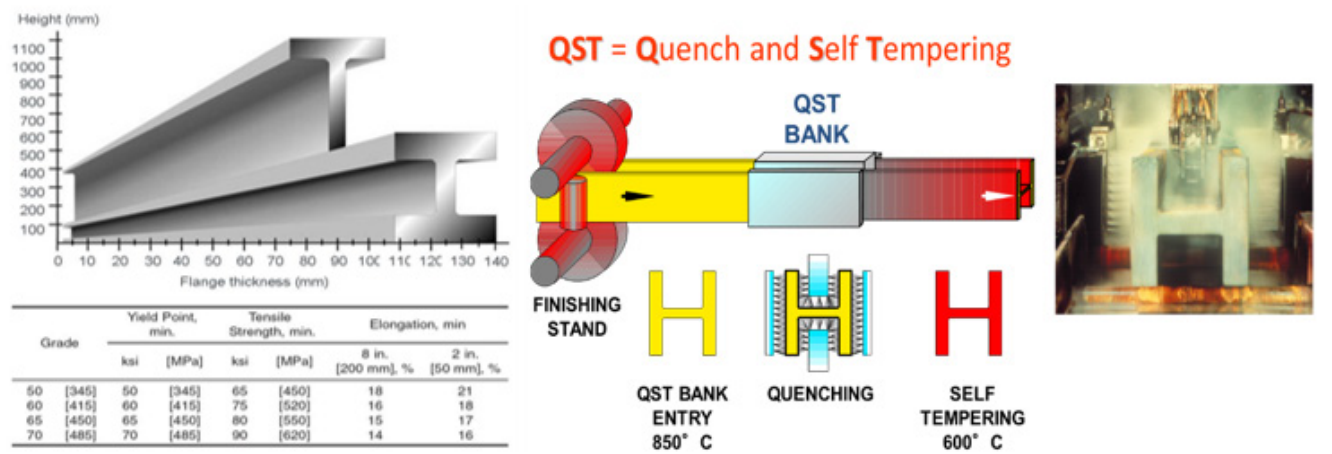

Figure 1: Left: Availability of Premium structural shapes according ASTM913. Right: schematic of QST process.

Beside the expansion of geometric properties, the development of optimized rolling procedures occurred over several decades. In particular the combination of thick material in high-strength steel (by maintaining ductility, toughness and compacity compliant to design requirements) is a technical challenge taken up by producer to follow the continuous strieve towards bolder structures [1]. Since the 1990, thermo-mechanical rolling has become a standard for the most advanced plants in Europe. In order to enhance the benefits of thermomechanical rolling, the quenching and selftempering process (QST) was developed specifically for sections with thick flanges [2] (Figure 1). Implementing this innovative procedure made it possible to economically obtain fine-grain high steel strengths (460MPa - Grade 65) for heavy sections (thinkness up to $140 \mathrm{~mm}$ ) without the costly addition of alloying elements. 
More recently higher grades (485MPa - Grade 70) have been successfully implemented in high-rise projects since 2015 and the strieve to develop higher strength (550MPa - Grade 80 ) has been already announced by steel producer [3].

\section{Welding and Detailing}

The development of improved steel grades was not only beneficial for designers but aimed also at achieving fit-for-use product. In fact, the thermo-mechanical QST process allows for low carbon equivalent content so easening up the welding process. For example, under given conditions, butt-welded joints can be realized without the need of constant pre-heating [4]. Concerning the fabrication of heavy sections, besides the technology of cold sawing and oxycutting, surfacic milling of the ends to create specific member connection types is widespread. The primary advantages of this complex technology are:
- Increase in working precision, therefore decreasing geometric tolerance issues;

- $\quad$ Create specific shapes for optimizing the welding procedure. In particular, more complex shapes than the classical $\mathrm{K}$ or $\mathrm{V}$ shape may be realized, decreasing the volume of welded material;

- $\quad$ Allowance of specific member connection needs, e.g. diagonal connection on gusset plates

- Minor impact on the metallurgy of the base material when compared to other working technology, such as oxycutting, This is particularly relevant for thick material with high strength;

- Follow severe standard specifications for fatigue design, e.g. in the case of a butt-weld connection thickness change.

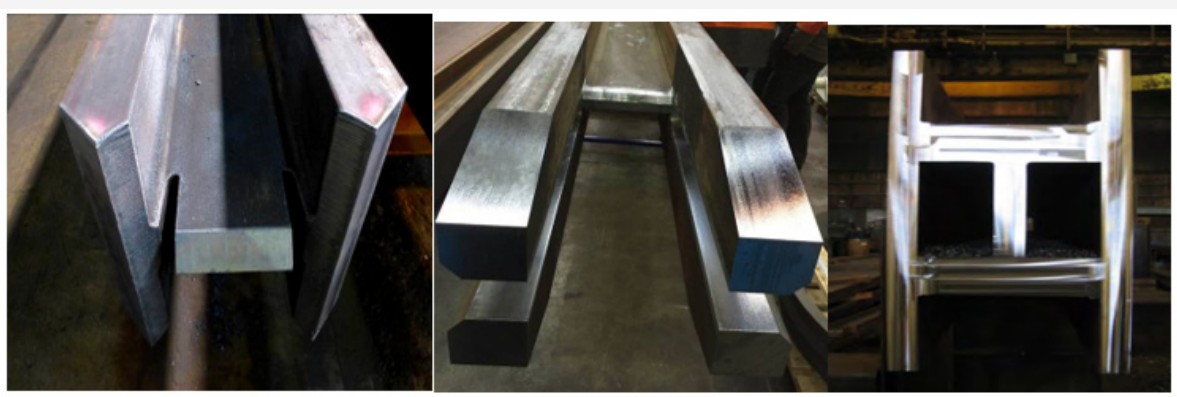

Figure 2: Left: Standard chamfering of Heavy Jumbo shapes by means of flame cutting. center: Diagonal of outrigger system with a milling connection detail to fit on a thick gusset plate. Right: fabrication of an heavy shape with heavy plates to obtain a reinforced column for the One World Trade Center [6]

The shape of the connection must be analyzed in detail and must comply with relevant welding and joint design standards (Figure 2). The possibility to limit preheating requirements and ensure perfect matching for welding was also the driver to develop Tailor-Made WTM [5]. This product responds to the need of designers or fabricators to combine structural shapes with plates to obtain special shapes for special applications but having exactly the same steel grade in terms of strength, chemical composition and welding properties (which was not the case before as sections and plates come from different plants). This complementary feature further enhances $\mathrm{H}$-structural shape the product of choice for highrise building projects [5]. To pick one example, if the One World Trade Center in New York would have been built today, the special columns made out of a core in heavy structural shapes reinforced by plates would have most probably been realized by the same steel grade from the same producer, providing benefits in terms of strengths and reducing substantially preheating requirements.

\section{High-Strength for Tall Building}

Heavy structural shapes in higher steel strength have been primarily developed to answer the structural needs for Tall buildings. Gravity columns, transfer and belt trusses, outriggers and all the structural parts designed mainly by axial forces are perfect applications for heavy structural shapes in higher steel strength. A recent iconic example is $150 \mathrm{~N}$ Riverside [3], which has been commissioned by Riverside Investment \& Development, is a 54-storey office building with approximately $111,000 \mathrm{~m}^{2}$ of rentable space. The building is designed by the architectural firm Goettsch Partners, with Magnusson Klemencic Associates serving as structural engineer of record. It is located on one of the most prominent sites in the city: the south branch of the Chicago River. The signature component of $150 \mathrm{~N}$ Riverside is the way the building appears to stand on one foot. With its vertical exterior columns seemingly terminating at level 8 , the building has a significantly smaller base when compared to the typical floors above. This special layout was required to accommodate the complexities of the building site. The project is located just metres away from the Chicago River at its east and a rail yard that has been active for more than a century at its west. The constraint of the railway, which made it impossible for the building's exterior columns to extend to solid ground, pushed the design team to develop what is known as a core-supported framing plan.

In the core-supported plan, the building was essentially designed as a typical office building from level 8 through level 54 with an efficient, yet complex, transfer truss system that enables the weight of the building to be supported on its concrete core below level 8 . The core is then supported on a $3 \mathrm{~m}$ deep concrete 
mat that transfers the load to a collection of 16 rock-socketed caissons below, each one having a $3 \mathrm{~m}$ diameter. The structural engineer, in cooperation with Zalk Josephs, the project's fabricator, determined that incorporating $70 \mathrm{ksi}$ steel sections into the design would lead to considerable savings in fabrication hours and cost. Prior to the material being specified on this project, A913 Grade 70 rolled shapes had been used on only two projects (both in Canada), so $150 \mathrm{~N}$ Riverside became the world's third project and the first in the United States to feature $70 \mathrm{ksi}$ rolled shapes. The project not only incorporates these one-of-a-kind specifications, but its design also uses some of the world's largest structural shapes: W36x925 and W14x873 sections in A913 Grades 65 and 70 [3] (Figure 3).

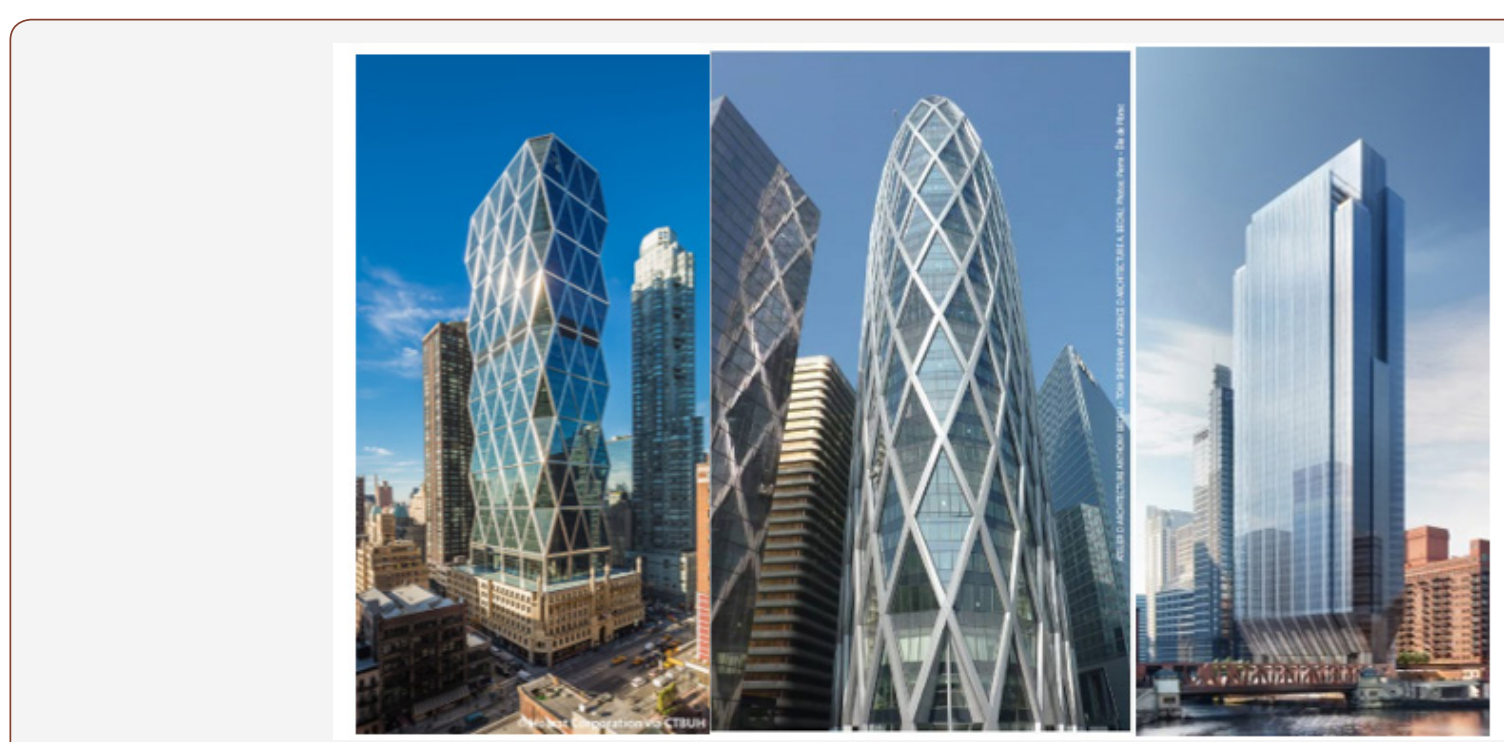

Figure 3: Left: Hearst Tower in NYC (USA) @Hearst Corporation; Center: Tour D2 in Paris (France) @ Atelier Architecture Anthony Bechu; Right: 150 N Riverside, Chicago (USA) @ Goettsch Partners.

\section{Acknowledgment}

The authors are thankful to all the colleagues, the partners and having contributed to the information and the project showed in this paper.

\section{Conflict of Interest}

No conflict of interest.

\section{References}

1. Bouchard S, Axmann G (2000) The Steel of Choice, Structural Engineer.
2. Axmann G (2003) Steel Going Strong, Modern Steel Construction.

3. Finnigan S, Charnish B, Chmielowski R (2015) Steel and the Skyscraper city - A study on the influence of Steel in the design of Tall buildings, CTBUH Conference, New York.

4. Donnay B, Axmann G, Hechler O (2015) The right choice of steel - according to the Eurocode.

5. Gerardy JC (2017) High-strength-web-tailor-made-wtm-to-complement-jumbo-shapes-for-supertall-slender-buildings, CTBUH Conference, New York.

6. https://constructalia.arcelormittal.com/en/case_study_gallery/united_states_of_america/one_world_trade_center_and_histar_steel_slender_safe_and_sustainable. 